\title{
Comments on Araco et al.: TVT-O vs TVT: a randomized trial in patients with different degrees of urinary stress incontinence
}

\author{
Claire Burton • Pallavi Latthe $\cdot$ Philip Toozs-Hobson
}

Received: 1 September 2008 / Accepted: 22 September 2008 / Published online: 9 October 2008

(C) The International Urogynecological Association 2008

\section{Dear Editor,}

We read with interest the paper by Araco et al. on a randomised trial of TVT-O versus TVT in patients with different degrees of urinary stress incontinence [1]. We compliment the authors on their rigorous trial design. We would, however, respectfully request clarification on a few points.

The operating time for TVT-O was significantly shorter than for TVT, but details on the anaesthetic were given only for one arm. Was anaesthetic time included in this, and if so was regional anaesthesia always used for both procedures? Clearly if anaesthetic time was included but some cases were performed under general anaesthesia, this would have an impact on operating times overall.

We were somewhat surprised by the number of reoperations $(30 \%)$ in the TVT SUI 1 group, which is high compared to other published data [2,3]. If only 4 of the 15 reoperations were for tape section and 3 for draining haematomas, the indications for the remaining 8 operations were not clearly stated. If $5.5 \%$ of TVT patients had surgery for early postoperative haematomas, this is a higher rate than in previously published reports $(0.7 \%-1.9 \%)[2,3]$. Do the authors have any explanation why surgical drainage rather than conservative management was chosen, or further information regarding the volume of haematoma and the drop in haemoglobin?

C. Burton $(\bowtie) \cdot$ P. Latthe $\cdot$ P. Toozs-Hobson

Urogynaecology, Birmingham Women's Health Care NHS Trust, Metchley Park Road, Birmingham B15 2TG, UK

e-mail: claire.burton@bwhct.nhs.uk
The authors state that there was no significant difference in reoperation rates between the TVT and TVT-O groups or between the SUI 1 and SUI 2 groups. However, we think that even if this was true at 1-year follow-up, the TVT SUI 1 group was more likely to require early reoperation for complications than the TVT-O SUI 1 group and the subjects in the TVT-O SUI 2 group were more likely to need a second continence procedure than all other groups.

Finally, stratification in a randomised controlled trial has many advantages, as demonstrated in this study, including avoiding confounding, and providing credibility to the choice of analysis covariates. One has to be aware, however, that there is more opportunity to introduce error and that the gain in precision of estimate of effectiveness is small once the number of subjects per treatment is over 50 [4]. An alternative method of obtaining comparable groups is minimisation.

Despite these points we would congratulate the authors on their excellent study and look forward to their 2- and 5 -year follow-up data.

\section{References}

1. Araco F, Gravante G, Sorge R, Overton J, De Vita D, Sesti F, Piccione E (2008) TVT-O vs TVT: a randomized trial in patients with different degrees of urinary stress incontinence. Int Urogynaecol J 19:917-926 . doi:10.1007/s00192-007-0554-y

2. Kuuva N, Nilsson CA (2002) A nationwide analysis of complications associated with the TVT procedure. Acta Obstet Gynecol Scand 81 (1):72-77

3. Tamussins KF, Hanzal E, Kolle D, Ralph G, Riss P (2001) Tension free vaginal tape: results of the Austrian registry. Obstet Gynecol 98:732-736

4. Matthews JNS (2000) An Introduction to randomised controlled clinical trials. Arnold, London 